\title{
La relación del jesuita José Mazo sobre la segunda toma de Colonia de Sacramento (1704-1705)
}

\author{
Martín Barrabino*
}

Colonia del Sacramento fue un enclave portugués fundado en 1680, sujeto a una constante lucha entre las coronas peninsulares por el control de la desembocadura del Río de la Plata y que incluso tuvo impacto en la Guerra de Sucesión española.

Un primer desalojo por parte de los españoles se produjo en 1680, apenas fundada la colonia. Efectivamente, luego de ser designado gobernador de la capitanía de Río de Janeiro el general Manoel Lôbo, recibió en 1678 precisas instrucciones de don Pedro II, príncipe regente de Portugal, a los fines de fundar un enclave urbano en la costa del Plata. De esta manera Lôbo llegó a la isla de San Gabriel el 20 de enero de 1680. Buscó un lugar apropiado en tierra firme y para el 4 de febrero ya estaban construidos dos galpones de techos de paja para los soldados y para el día 10 habían concluido cuatro casas, una de las cuales era para los padres de la Compañía. Los españoles de Buenos Aires reaccionaron inmediatamente y luego de algunas conversaciones diplomáticas con el gobernador José de Garro se inició la avanzada española en la mañana del 7 de agosto. Intervinieron guaranís de los pueblos jesuíticos, e incluso el superior de las misiones P. Pedro de Orduña, entre otros tres jesuitas. La contienda duró apenas una hora, quedando un centenar y medio de muertos, además de heridos y prisioneros (Page, 2014, p. 14).

Pero la decisión final de la toma se haría en Lisboa donde la corona española restituiría Colonia a Portugal. El 12 de febrero de 1683 el gobernador de Río de Janeiro, Duarte Teixeira Chaves recibió Colonia y el día 18 partió de allí a Buenos Aires el capitán Cristóvão de Almeida a hacer lo propio con los prisioneros que habían sobrevivido, pues algunos se fugaron, otros se murieron y los esclavos fueron vendidos. Entre ellos estaban los jesuitas PP. Pedroso y Alvares que volvieron a Colonia, luego de dos años y medio de au-

\footnotetext{
* CIECS-CONICET/UNC. E-mail: mbarrabino@ hotmail.com
} 
sencia. En un catálogo jesuita de 1683 se menciona la casa de los jesuitas, indistintamente como "Residência do Rio de la Prata" o "Residência da Nova Colónia dos Portugueses"

La segunda toma española de Colonia del Sacramento tuvo, como dijimos, repercusiones internacionales. De allí que abundan las fuentes documentales, descripciones y trabajos historiográficos. El primer impreso se publicó en Madrid en 1705, es decir inmediatamente de finalizada la contienda en dos obras realizadas en talleres diferentes. Uno de Joseph Contreras y otro de A. Bizarrón. Obviamente refleja la visión oficial de los hechos. Al igual que otra Relación aparecida el mismo año en Lima. Otro tipo de impresos que detallan los acontecimientos son por ejemplo la "Certificacion Authentica" que firmó Baltasar García Ros y que no es más que un breve relato de cuatro hojas del mismo año. Una certificación anterior es la de Esteban de Urizar y Arespacochaga que recién la publicó el P. Pastells (1933, V, pp 60-63), alabando la intervención de los indígenas. Como también lo certifica Andrés Gómez de la Quintana en el mismo año, aunque tampoco impresa en su tiempo (Bauzá, 1965, II, pp. 366-370). Entre las relaciones oficiales se destacan la de Alonso Valdés e Inclán, gobernador de Buenos Aires, que en realidad son cartas dirigidas al virrey del Perú con críticas a la indisciplina de las tropas guaranís (Thun et. al. 2015, p. IX).

Sobre las fuentes portuguesas del acontecimiento, Ferrand de Almeida (1973), compiló 156 excelentes documentos y finalmente Thun (et. al. 2015) publicó un texto anónimo en lengua guaraní, seguramente escrito por un jesuita a los fines de leerse en las reducciones. Pareciera obvio que su autor pudo ser alguno de los protagonistas de la gesta, entre ellos el jesuita superior José Mazo, del que aquí presentamos su breve visión de los acontecimientos y que no solo permaneció inédito hasta ahora sino ignorado por gran parte de los historiadores del tema. Difiere sustancialmente de los otros al relatar hechos muy particulares sobre los indígenas, como que llevaron sus propios caballos y comida, siendo que los españoles no les proveyeron de nada.

Para el segundo desalojo de Colonia y por mandato del gobernador Valdés Inclán y a las órdenes del sargento mayor Baltasar García Ros, llegaron a las afueras de Colonia en noviembre de 1704, la suma de 4.000 indios armados, que llevaron 6.000 caballos, casi 2.000 mulas y varias embarcaciones, además de provisiones a su costa que incluían 30.000 vacas para sustentase ellos y los españoles. El sitio duró ocho meses y esta vez murieron 130 indios, quedando 200 gravemente heridos. En el informe del gobernador del Tucumán don Esteban de Urizar y Arespacochaga, expresa que el 8 de setiembre marcharon tres cuerpos de soldados teniendo como capellán al jesuita italiano P. Pablo Restivo (Caltanisetta, 1658-Candelaria. 1740). Estuvieron a cargo los caciques de San Borja, San Miguel, Candelaria y Yapeyú: Diego Gaybipoi, Bonifacio Capi, Juan Mañari y Pedro Mbacapi. Irían en calidad de capellanes jesuitas, el francés José de Tejedas (Perpiñán, 1664Candelaria, 1744), los españoles Juan de Anaya (Sevilla, 1667-San Borja, 1742), y quien llegó a provincial el P. Jerónimo Herrán (Santander, 1672-Córdoba, 1743) y Pedro (o Francisco) de Medina (Santiago del Estero, 1637-San Carlos, 1717).Además de los coadjutores "cirujanos" Pedro de Montenegro (Galicia, 1663-Mártires, 1728), Joaquín de Zubeldía (Tolosa, 1657-San Borja, 1732) y José Brasaneli (Milán, 1658-SantaAna, 1728). El verdadero médico era el H. Montenegro, que había estudiado medicina en el Hospital General de Madrid, mientras que los otros dos posiblemente eran ayudantes, de hecho Brasaneli era un eximio artista. Agrega el P. Furlong que en aquella oportunidad el H. Montenegro "ayudó a 
200 heridos y a muchos enfermos de epidemias", especialmente disentería (Page, 2014, p. $15)$.

Un documento del P. Nusdorffer ${ }^{1}$, relacionado a los servicios que prestaron los guaranís a la corona desde 1637, no menciona la ferocidad con que los indios arrasaron Colonia, pues según informó el gobernador de Buenos Aires al virrey, tanto españoles como jesuitas intentaron que no entraran los guaranís a la ciudad, mientras los portugueses huían.

Pero no pudieron contenerlos con persuasión y saquearon y quemaron casas, además de entrar a la iglesia rompiendo cuanto encontraban y cargando con lo poco que habían dejado. Los soldados se fueron y el P. superior José Mazo quedó solo junto a sus compañeros de religión. Finalmente el virrey informó al rey que según le trasmitió el gobernador Valdés Inclán en carta del 28 de mayo de 1705 "concluyó la demolición de la fortaleza, dejándola toda arrasada y llevándose a Buenos Aires todos los pertrechos que se hallaron en ella" (Pastells, 1933, V, p. 95).

El documento transcripto, es una relación redactada y firmada por el P. José Mazo, jesuita nacido en Alcona, provincia de Castellón en España, el 12 de enero de 1658. Ingresó a la Provincia jesuítica de Aragón en 1679, llegando a Buenos Aires dos años después en la expedición de los PP. Tomás Donvidas y Cristóbal de Grijalba. Obtuvo su sacerdocio del obispo de Buenos Aires Antonio de Azcona Imberto en 1686 y su cuarto voto en 1695, falleciendo mártir en el río Paraná el 10 de setiembre de 1717 (Storni, 1980, p. 181 y Techo y Orosz, 1759, pp. 92-94).

El P. Mazo, como superior de la misión, realizó la siguiente descripción de lo que hicieron los guaranís cristianos a cargo de la Compañía de Jesús de la Provincia de Paraguay. Participaron por orden del gobernador de Buenos Aires Valdés Inclán en la conquista de la colonia portuguesa, durante el sitio ocurrido entre abril de 1704 en que se declaró la guerra y marzo de 1705 en que se decidió la destrucción de la fortaleza. En este sitio participaron españoles pagos, que llegaron desde las ciudades de Buenos Aires, Santa Fe, Corrientes y Córdoba. A su vez fueron enviados desde las misiones jesuíticas, alrededor de cuatro mil guaraníes. Todos estos hombres llegaron a las cercanías de la isla San Gabriel, junto con caballos y mulas, sus propias armas y su manutención costeada por ellos mismos, sobre todo yerba y tabaco. Los indios de las misiones llegaron en dos grupos, unos por el Paraná y otros por tierra. Con ellos fueron designados por superiores, cuatro sacerdotes como capellanes: Pedro de Medina, José de Tejedas, Juan de Anaya, y Jerónimo de Herrán, junto con ellos también fueron tres hermanos coadjutores para asistencia de heridos: Joaquín de Zubeldia, José Brasanelli y Pedro de Montenegro. Para totalizar los nueve religiosos que formaron parte del ejército, el P. Pablo Restivo fue por capellán de los españoles y como superior, tanto de sacerdotes y coadjutores, fue el mencionado P. Mazo. Durante el tiempo que duraron los ataques, donde los guaranís y españoles trabajaban en forma desigual, la manutención se pudo hacer porque aquellos juntaban ganado de sus vaquerías, como la madera necesaria para las viviendas, capillas, hospitales y armado de la defensa

\footnotetext{
${ }^{1}$ AGN, S. IX, 6-9-7, Doc. 60 "Relacion compendiosa delos servicios q han hecho â su Magd. los Indios delas Doctrinas, q estan â cargo delos PP. dela Compa. de Jesus en esta Provincia del Paraguay de Nacion Guaranis, ô como los llaman vulgarmente tapes, desde el año 1637 hasta Otubre del presente 1735, así en el distrito del Govierno de Buenos Ayres, como en el del Paraguay" 1735. Publicado en parte por Hernández, 1913, T. II, pp. 63-73.Teschauer, 1922, T. III, pp. 157-173, entre otros.
} 
ante los ataques y en acarrear, componer los elementos necesarios para el combate: pólvora, tacos, tablas, palos, explanadas, cestones, la artillería con la ayuda en ciertos casos de animales de carga. Esto resalta la constancia que tenían los guaraníes, que se mantuvieron todos hasta que el gobernador los despachara de regreso a sus pueblos.

Los indios fueron fundamentalmente soldados, dado que entraban cada día de guardia en los ataques y baterías, con sus armas, algunas de fuego, otras lanzas, macanas, piedras y flechas. Se les indicaba sitio que guardasen sin que jamás lo desampararan, y desde las mamposterías tiraban a los portugueses, matando a muchos de ellos aunque con alguna perdida de los indios.

Finalmente el enfrentamiento cesó, pero la historia de la ocupación continuó varios años más.

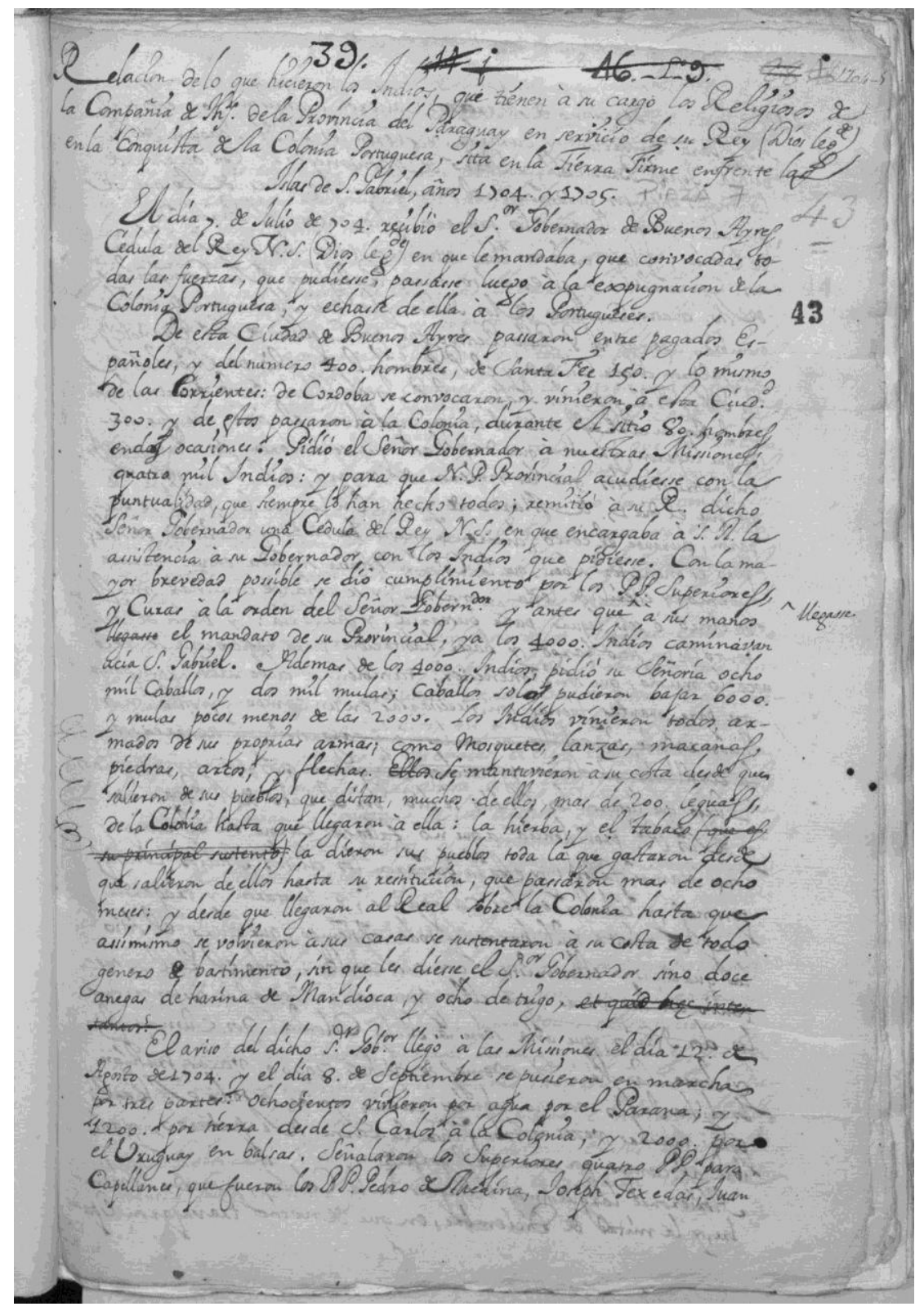

161 Martín Barrabino. Relación del jesuita José Mazo sobre la segunda toma de Colonia ... 158-171. 
[f. 43] Relacion de lo que hicieron los indios, que tienen a su cargo los Religiosos de/la Compañía de Jesus de la Provincia del Paraguay en servicio de su Rey (Dios le guarde)/en la Conquista dela Colonia Portuguesa, sita en la Tierra Firme enfrente las/ islas de San Gabriel $^{2}$, años 1704 y $1705^{3}$.

El dia 7 de Julio de 1704 recibió el Señor Gobernador de Buenos Ayres/Cedula del Rey Nuestro Señor (Dios le guarde) en que le mandaba, que convocadas to-/das las fuerzas, que pudiesse, passasse luego a la expugnacion de la/Colonia Portuguesa, y echasse de ella a los Portugueses./

De esta Ciudad de Buenos Ayres passaron entre pagados Es-/pañoles, y del número 400 hombres, de Santa Fe 150 y lo mismo/de las Corrientes: de Cordoba se convocaron, y vinieron a esta Ciudad/300 y de estos passaron á la Colonia, durante el sitio 80 hombres/en dos ocasiones. Pidió el Señor Gobernador á nuestras Missiones/ quatro mil indios: y para que Nuestro Padre Provincial ${ }^{4}$ acudiesse con la/puntualidad, que siempre lo han hecho todos; remitió a su Real dicho/Señor Gobernador una Cedula del Rey Nuestro Señor en que encargaba a su Reverencia/la asistencia a su Gobernador con los Indios que pudiesse. Con la mayor brevedad possible se dio cumplimiento por los Padres Superiores/y Curas a la orden del Señor Gobernador y antes que llegase a sus manos/llegasse [testado: llegasse] el mandato de su Provincial, ya los 4000 indios caminaban/acia San Gabriel. Ademas de los 4000 indios pidió su Señoria ocho/mil caballos, y dos mil mulas; caballos solos pudieron bajar 6000/y mulas poco menos de las 2000. Los indios vinieron todos ar-/mados de sus propias armas; como mosquetes, lanzas, macanas,/piedra, arcos, y flechas. [Testado: Ellos] Se mantuvieron a su costa desde que salieron de sus pueblos, que distan, muchos de ellos, mas de 200 leguas $^{5}$ de la Colonia hasta que llegaron a ella: la hierba, y el tabaco [testado: que es/su principal sustento] la dieron sus pueblos toda la que gastaron desde/que salieron de ellos hasta su restitucion, que passaron mas de ocho/meses: y desde que llegaron al Real sobre la Colonia hasta que/assi mismo se volvieron a sus casas se sustentaron á su costa de todo/genero de bastimento, sin que les diesse el Señor Gobernador sino doce/[f]anegas de harina de Mandioca, y ocho de trigo, [testado: ilegible]/

El aviso de dicho Señor Gobernador llegó á las Missiones el dia 12/de Agosto de 1704 y el dia 8 de septiembre se pusieron en marcha/por tres partes: ochocientos vinieron por agua por el Parana; y/1200 por tierra desde San Carlos ${ }^{6}$ a la Colonia; y 2000 por/el Uruguay en balsas. Señalaron los Superiores quatro Padres para/Capellanes, que fueron los Padres Pedro de Medina ${ }^{7}$, Joseph Texedor ${ }^{8}$, Juan/[f. 43v] de Amaya ${ }^{9}$, y Geronimo de

\footnotetext{
${ }^{2}$ San Gabriel es una pequeña isla del Río de la Plata, perteneciente a Uruguay. Está ubicada a tres kilómetros de punta San Pedro, en las cercanías de Colonia de Sacramento.

${ }^{3}$ ANCh, Jesuitas Argentina, vol 197, n. 7, ff. 43-48v.

${ }^{4}$ Era el segundo mandato del P. Lauro Núñez, entre 1702 y 1706.

${ }^{5}$ Una legua castellana equivale a 4.190 metros.

${ }^{6}$ Misión de San Carlos, estaba ubicada en la provincia de Corrientes, siendo fundada en 1631 como una de las misiones establecidas por los jesuitas con indígenas guaraníes durante la dominación colonial española.

${ }^{7}$ En realidad es el P. Pedro de Medina, nacido en Santiago del Estero en 1637 y fallecido en la reducción de San Carlos en 1717. Ingresó a la Compañía de Jesús de la Provincia del Paraguay en 1653, alcanzando su sacerdocio en 1664. Sus últimos votos los profesó en la reducción guaraní de Encarnación de Itapúa en 1670 (Storni, 1980: 181-182).
}

162 Martín Barrabino. Relación del jesuita José Mazo sobre la segunda toma de Colonia... 158-171. 
Herran $^{10}$. Salieron assi mismo con ellos tres/hermanos para cuydarlos y curarlos, y fueron los hermanos Joaquin de Su-/beldia ${ }^{11}$, Joseph Brasaneli ${ }^{12}$ y Pedro de Montenegro ${ }^{13}$. Con ocasión de/los malos tiempos tardaron en el camino mucho mas delo que se/pensaba, con que llegaron los primeros ochocientos del Parana a 27/de Octubre; y luego en breves dias estuvieron todos los quatro mil jun-/tos. Concurrieron en el exercito nueve Religiosos dela Compañía de Jesus, quatro Capellanes de los indios y los tres Hermanos que arriba/nombré, ademas el Padre Pablo Restivo ${ }^{14}$ fue por Capellan delos Españoles/que salieron deesta Ciudad, y el Padre Provincial señaló por superior de/los Padres y Hermanos y de los indios, al Padre Joseph Mazo ${ }^{15}$. Se mantuvieron/los indios en el Real todo el tiempo que duró el sitio que fue des-/de que llegaron, ya dixe quando, hasta que se huyeron los Portugueses/en quatro navios que los vinieron de socorro, del Rio Geneyro,/que fue el dia 27 de marzo de 1705. En lo que los indios se ocu-/paron durante el cerco, dixe con la mayor brevedad y claridad possible,/pero es menester saber, que la Colonia estaba situada en un parage/yermo, y esteril de leña y madera, y se avia de caminar mas/de cinco ó seis leguas para buscarla, y hallarla: y para el sus-/tento de un sitio largo y hacer habitacion para tantos, ya se reco-/noce lo mucho, que seria menester: tambien se debe saber y suponer/que para quantas faenas son necessarias en un campo y sitio, no/huvo [testado: en este ni caballos, ni mulas que cargassen y acarreassen/la cavalleria ni demas pertrechos de guerra] otros portadores que los indios./Luego que llegaron los indios se dio por el cabo del exercito/y de los Padres providencia a que no faltasse carne en el campo,/como xamas faltó: y esta la buscaron los dichos indios con sus/personas y caballos en las campañas, y juntaron y trage-

${ }^{8}$ El jesuita francés José de Tejedas nació en Perpiñán en 1664, ingresando a la Compañía de Jesús de la Provincia de Aragón en 1679. Llegó a Buenos Aires en 1691 en la expedición del P. Antonio Parras. Profesó su cuarto voto en 1705 y falleció en la reducción de la Candelaria en 1744 (Storni, 1980: 281).

${ }^{9}$ El P. Juan de Anaya nació en Sevilla en 1667, ingresando al Instituto en 1681 y llegando a Buenos Aires cuatro años después en la expedición del P. Diego Centeno. El obispo Azcona lo ordenó sacerdote en 1692 y sus últimos votos los profesó en 1705. Misionero incansable falleció en la reducción de San Borja en 1742 (Storni, 1980: 13).

${ }^{10}$ El P. Jerónimo de Herrán nació en Pámanes, provincia de Santander en España en 1672, ingresando a la Provincia Jesuítica de castilla en 1688. Llegó a Buenos Aires en 1698 y allí mismo profesó su cuarto voto en 1711. Fue Procurador en Europa entre 1725 y 1729 y al regresar fue designado provincial hasta 1733. Falleció en Córdoba en 1743 (Storni, 1980: 140).

${ }^{11}$ El H. Joaquín de Zubeldía, nació en Tolosa en Guipúzcoa en 1657, ingresando a la Provincia de Toledo en 1680. Cinco años después llegó a Buenos Aires en la misma expedición del P. Anaya. Profesó su cuarto voto en la reducción de Apóstoles en 1695, falleciendo en la de Apóstoles en 1732 (Storni, 1980: 315).

${ }^{12}$ El famoso artista y arquitecto José Brasanelli nació en 1658 Milán, donde ingresó a la Compañía de Jesús en 1679. Sus últimos votos los profesa en Sevilla antes de embarcarse en 1690, arribando a Buenos Aires al año siguiente en la expedición del P. Antonio Parra. Falleció en la reducción de Santa Ana en 1728 (Storni, 1980, p. 43) y recientemente (Sustersic, 2017).

${ }^{13}$ El acreditado médico Pedro de Montenegro nació en Santa Marina de Galicia en 1663, ingresando a la Compañía del Paraguay en 1691, profesando sus últimos votos en la reducción de Concepción en 1703. Murió en la de Mártires en 1728 (Storni, 1980: 190).

${ }^{14}$ El italiano P. Pablo Restivo nació en Mazzarino en 1658, ingresando al Instituto en Sicilia en 1677. También y como otros aquí mencionados llegó a Buenos Aires en 1691en la expedición del P. Parra. Su cuarto voto lo profesó en Candelaria en 1694, alcanzando a ser superior de las misiones en el periodo 1818-1720. Veinte años después falleció en Candelaria (Storni, 1980: 236).

${ }^{15}$ Del P. José Mazo nos referimos en la introducción.

163 Martín Barrabino. Relación del jesuita José Mazo sobre la segunda toma de Colonia... 158-171. 
ron/mas de treinta mil bacas, y todo el tiempo, que duró/el sitio las guardaron ellos mismos con sus caballos. Todo el Real se sus-/tentó con las vacas, que ellos juntaron; ademas se sustentaron/en los dos Navios, que avia sobre dicha Colonia, dos sumacas $16 / y$ cinco lanchas. Y ademas de dichas 30.000 vacas traían/los dichos indios con sus caballos carne gorda a todo el Real;/porque muchas veces estaba flaca la carne del pastoreo, y assi/iban al cambo por una mas gorda./

Abrieronse larguissimos ataques en la Colonia, y sacado Noviem-/bre y la mitad de Diciembre, en que de noche travajaron Espa-/[f. 44]ñoles con indios, todo lo restante del tiempo, que siempre huvo que/travajar hasta 10 de Marzo, lo travajaron solos los indios de/dia y de noche. Se traxeron para los ataques mas de cien mil fagi-/nas ${ }^{17} \mathrm{y}$ todas las cortaron, o hicieron los indios, y mas de ochen-/ta mil las cargaron a hombros, por mas de legua y media, y dos/leguas, y las otras veinte mil las traxeron en barcos hasta la ribera,/y de ella al Real en carretas, y de este a los ataques que dis-/taban mas de tres quartos de legua, las llevaron los indios a hom-/bros. Dispusiéronse seis baterías, y quanto en ellas se gasto y tra/vajo, hicieron y acarrearon los indios: toda la polvora, las balas,/tacos, tablas, palos, esplanadas, cestones, todo lo cargaron á hombros,/ y aun toda la artilleria la tiraron a mano desde el Real a las/baterías y de unas a otras, haciendo en todo, lo que en Europa/las acemilas ${ }^{18}$ y bueyes. No se descomponian vez alguna las/baterias y esto succedia frequentemente, que no las compusies-/sen ellos: y bien saben los expertos el riesgo que ay en esto;/los cestones los llenaron ellos, expuestos al tiro del cañon y del/fusil, de que murieron muchos. Las baterias hechas en salchi-/chas y faginas ordinarias, las hicieron ellos siempre como todo/lo demás de estas faenas. Sino hubiera visto lo mucho que tra-/vajaron en manejar la artillería de una parte a otra, no lo cre-/yera: á las vezes, ni 50 indios, ni a vezes 100 podian con un cañon; por los ataques, y arenales a ellos immediatos, y to-/do lo vendieron, llevados del amor a su Rey, y Señor natural;/y todos admiraban la constancia de los dichos, sabiendo lo incons-/tante del natural de los indios, y se mantuvieran todos hasta el dia 17 de Marzo, que los despachó a sus pueblos el Señor Gober-/nador.

Lo mas dificultoso en el sitio era el sustentar de leña a tantos,/y hacerles viviendas contra las inclemencias del tiempo, uno/y otro hicieron los indios, y para todos juntaron, y traxeron/leña y la mas sobre sus hombros; para todos ellos hicieron ca-/sas e iglesias bien capazes, y casas para sus Capellanes, y hos-/pitales para sus enfermos, y lo mismo hicieron para los Espa-/ñoles; á estos les ayudaron á hacer sus casas, é hicieron la del/ Señor Gobernador y su familia, y le assistieron en sus personas/quantas huvo menester para su servicio, le traxeron leña en/[f. 44v.] abundancia, y agua y carne, y lo demás que fue necesario./

Desde el primer dia en que se comenzó a travajar se dividie-/ron los indios en quatro trozos, y para el buen gobierno, el/uno de ellos se destinaba cada dia para lo que en el campo/se offrecia de travajo. Estos cargaban desde el Real quanto/avia que llevar a los ataques, y baterías, quanto avia que/acarrear del rio, trahido en las lanchas de Buenos Ayres/al Real,

\footnotetext{
${ }^{16}$ Sumaca es barco pequeño y plano, muy usado para cabotaje en el Río de la Plata y las costas del Brasil sirvió también para travesías oceánicas tanto como mercantes como buques de guerra.

${ }^{17}$ Faginas es una leña ligera para encender el fuego.

${ }^{18}$ Acémilas es una bestia de cargas o mulas.
}

164 Martín Barrabino. Relación del jesuita José Mazo sobre la segunda toma de Colonia ... 158-171. 
y lo que de este a las lanchas, estas cargaban y des-/cargaban, manejaban las carretas, y trahian y hacían quan-/to avia que hacer, y traer de una parte a otra.

Con aver sido tantas las faginas que se hicieron, fueron muchas/mas las estacas, pues como bien saben las que se han hallado en/sitios a cada fagina le corresponden dos y tres, y mas estacas; estas/todas las cortaron los indios, y las acarrearon de mas de cinco/leguas, bien que en carretas, y para muchos cestones que se hi-/cieron, ellos cortaron las varas, y estacas, que todo fue muchis-/simo, y hechos los cestones, los llevaron á las baterías. Como/los ataques eran tan largos, eran necesarias muchas mamposterías./y sin immensos sacos de tierra no se podían hacer, hicieron los/indios muchissimos millares de ellos, los llevaron a los ataques,/ y llenaron de tierra con mucho travajo; todas estas faenas que/digo las hicieron solos, sin ayuda de nadie, y lo mismo se tendrá/dicho de las demás, en no diciendo lo contrario. Para una/batería, que fue inútil, travajaron sin medida los indios en hacer/un altíssimo respaldo, para resguardar dicha batería de dos ba-/luarte, por mas de diez y ocho días, con mucho riesgo, y afán./ Juzgó por conveniente el Señor Gobernador el dejar los ataques, que/llegaron á menos de tiro de pistola dela Colonia; y a el passo que/fue mucho lo que en ellos y baterías se puso y metio, a ese/passo fue muchissimo lo que los indios travajaron en retirarlo/todo en breve tiempo, que nos admiró a todos. Dispuso su/Señoria acordonar la gente a tiro de fusil dela Colonia, en/una cortadura, que los Portugueses hacían: y para que en dicho/sitio estuviessen seguros los Españoles y indios, se corrió una fuerte/trinchera por mas de 500 baras, puso en dos parages de ellas/[f. 45] Artillería, y quanto se travajó en uno y otro, lo hicieron los indios./El manejo de tanto afán ya se reconoce; pero la constancia en su-/frir los soles, aguaceros, vientos, fríos, de noche con la poca leña/y abrigo, no fue menor, y en esto fueron iguales con los Españoles/que assistian en las guardas y ataques./

No solo hicieron los indios officio de gastadores sino también/de soldados: entraban cada dia de guardia en los ataques y bate-/rías 300 á vezes 400 ó los que pedía el cabo principal del Exer-/cito: estos entraban con sus armas, unas de fuego, y otras, lanzas,/macanas, piedras y flechas. Hacían sus centinelas con tanto cuy-/dado, y vigilancia, que decían a voces todos los Españoles, y en/especial los cabos que eran para dicho ministerio mas apropósito/que los Españoles. Se les señalaba sitio que guardasen y guar-/daran siempre el que les cupo, sin xamas desampararlo: delas/mamposterías tiraban también a los Portugueses, y mataron á/muchos, aunque con alguna perdida delos indios. Estos xamas tira-/ban al ayre, y todos los Españoles, y los cabos admiraban la constan-/cia para lograr un tiro; pues se ponían casi en cueros assandose al/sol, esperando en lo mas riguroso de el dia, para tirar, y ma-/tar algún Portugues. Les duró esta constancia todo el tiempo/que duró el sitio; y sucedia todos los días el irse a los ata-/ques muchos indios, que no estaban de guardia a hacer lances/en los Portugueses. Lo que á todos admiraba era el poco miedo,/que los indios tenían a los Portugueses, y sus balas; siempre ca-/minaban avista dela fortaleza, y expuestos al tiro de cañon,/ y aunque muchas vezes les tiraban no quiso Dios, que pereciesse alguno; y viendo los Portugueses, que de sus tiros, no conse-/guían sino la gritería, y la burla que con sus camisetas hacían/de ellos, dejaban de tirarles muchas vezes. Mostraron en mu-/chas ocasiones su valor, y ningún temor a los Portugueses; la pri-/mera ocasión fue como ahora dixe./

Los portugueses, aunque sitiados salían fuera de la Colonia,/como tres ó quatro quadras, unas a pie y a caballo otros, y fuera/de dicha Colonia tenían en un gran monton de 
tierra, que les/avia de servir de reducto, su centinela, ó centinelas; passaban los/Portugueses todo el sitio delas quatro, ó mas quadras, xamas/[f. 45v.] los Españoles se animaron a inquiertales; pero nuestros indios lleva-/ron a mal semejante atrevimiento Portugues, y una mañana viendo-/lo yo, y casi todos los Españoles, salieron al puerto delos Portugue-/ses otros tantos indios a caballo, incitando estos a aquellos, unos/y otros procuraban atraher para su sitio a sus contrarios; y no/pudiendo recabar los indios [testado: atraer para su sitio a sus contrarios]/el apartar a los Portugueses del suyo, se acercaron ellos, pero un/Portugues infante con una escopeta bien larga les disparaba, y no/logró tiro alguno, antes consiguió muchos chiflidos, como esta-/ban los indios, y viendo estos que no conseguían cosa, se fueron/á su Real, y luego volvieron con dos indios infantes cada uno/con su boca de fuego: llegaron al sitio delos Portugueses los dos in-/dios de apie con dos tanto valor, que no dudaron de encaminarse/acia los Portugueses, y se afrontaron con el infante, que disparaba/á los de apie, que se dieron tan linda maña, que haciendo todos/aun tiempo la puntería, no le dieron lugar al Portugues, para/disparar su fusil, porque se lo hicieron pedazos, y le hirieron/de muerte, y oí decir que murió. Traxeronse los pedazos del/fusil, que tuve en mis manos, y los puse en las del cabo princi-/pal de nuestro Exercito. Desde este dicho dia no salio Por/tugues alguno fuera dela Colonia, y se retiraron las centinelas/que tenían fuera de ella: el indio que hirió al Portugues, y/quebró su fusil, se llama Estanislao, es de San Nicolas./

Tambien el siguiente caso, es prueba del valor de nuestros/indios: travajaban estos de dia en los ataques divididos en/dos partes, o ramales, como llaman los militares: avia en uno/de dichos ramales, por guarda de él, y delos indios, trava-/jadores una Compañía de Españoles de Santa Fe, y por su Capitan/tenia a Don Manuel de Amilivia ${ }^{19}$; el dia 30 o 31 de Diciem-/bre a la una del dia, hicieron salida los Portugueses á nuestros/ataques, y la lograron tan bien, que sin ser vistos ni sentidos/se entraron en ellos, dejando muertos dos Españoles, que paga-/ron su descuydo con la vida, pues debiendo velar, dormian;/hirieron de muerte a 14 Indios de San Cosme, y de ellos mu-/rieron seis el mismo dia, y dos el dia siguiente. Solo quatro/[f. 46] indios pudieron coger sus armas, y se pusieron en defensa; quienes al/ver quelos Portugueses se llevaban preso y herido a su Lenguaraz Cor/rentino, les embistieron, y con una desjarretadera le liberaron, quitando/dos espadas, un alfange, y una pistola á los Portugueses. Los Indios/que assistían en el ataque eran de travajo, y solos avía en dicho/ramal veinte y dos, aviendo ido otros por agua. Con repentina in-/vasión delos Portugueses, huvo algún desorden en la Compañía de los Españoles de/SantaFee, que trataron de retirarse, con perdida de su Capitan que quedó/muy mal herido, y se lo llevaron los Portugueses á su Colonia, y de a/llí al Brasil, quando abandonaron la Plaza. Retiraronse también/principalmente los demás indios, quedando solo su Capitan llamado/Joseph Ara$\operatorname{sogue}^{20}$, natural de San Nicolas, [Testado: se quedó en el ataque], y co-/giendo su escopeta se salió del ataque, y hizo frente, y detuvo a catorce/Portugueses, que a dicho ataque se encaminaban; ya amagaba a uno, y ya/a otro, y con su continuo movimiento no les dio lugar á quele hicies-/sen puntearía, y le tirassen, y así los detuvo, hasta tanto que avisado/el Cabo principal del Exercito, envió en su socorro al Capitán/Don Bartholome de Aldunan$\mathrm{te}^{21}$, con una manga de soldados de sus compa-/ñía, y al Capitan Don Andres dela Quinta-

\footnotetext{
${ }^{19}$ Don Manuel de Amilivia:

20

21
}

166 Martín Barrabino. Relación del jesuita José Mazo sobre la segunda toma de Colonia... 158-171. 
$\mathrm{na}^{22}$ : quando reconoció el/Indio, que ya tenía socorro, disparó su escopeta, y se retiró dentro el/ataque, y fue el tiro tan bueno que mato un Portugués, como lo dixo o-/tro que se rindió el día 19 de Noviembre de 1704. Todos aplaudieron/el hecho del Indio, y el cabo del exercito le dio muchos abrazos,/y el Señor Gobernador le confirmó el título de Capitán que ya tenía./

Sobre todo lo que mostró mucho el valor delos Indios, fue/el sucesso del día 24 de Noviembre de 1704, y aun tocó en barbaria/por no averse sabido retirar a tiempo: fue el caso: dentro dela Colonia/avía algunos Indios fugitivos delas Missiones: estos de noche tuvieron/modo de hablar á algunos delos Nuestros, y mostrándose deseosos de/labar su maldad, con mostrarle camino para coger la Colonia, les fac-/ilitaron mucho la entrada, y aun les descubrieron algunas minas y ca-/minos secretos: hablaron los que fueron engañados con el restante número/de Indios y prometieron feliz successo: diose de todo noticia al Cabo principal, y gozoso mandó que solos 500 por una parte, y/otros tantos por otra, acometiesen a media noche del día 23 de No-/viembre en la hora que estaba dispuesto a coger un Navío Portugués a-/marrando con tres amarras bajo de tres baterías, y lo cogieron los/de Don Joseph de Ibarra ${ }^{23}$, y diez y seis hombres que se vinieron huidos/[f. 46v.] del Rio Geneyro, delos de Pallo, con poca perdida nuestra, y mucha/delos Portugueses. Quando se executó la toma del Navío, avisaron/á los Indios que se hallaban por el Sur, que acometiesen, y o no en-/tendieron lo que les dixo, ó, no los avisaron, ó no se porqué no/acometieron; los del Norte acometieron, pero luego se retiraron porque/fueron sentidos. Ya estaban todos los Españoles persuadidos, que no aco-/metieran los Indios, quando una hora antes del amanecer cerraron/todos por una y otra parte con la Colonia, y no solo los 500 por/cada parte, sino todos los 4000. Porque no fue possible detenerlos/llegaronse hasta los muros y fosos, y se hallaron burlados y vendidos/delos Indios fugitivos en la Colonia, intentaron muchas veces subir/por los muros y no pudieron, arrimaron sus picas, y tampoco pu-/dieron hasta el echar lazo en algunos cañones executaron; y vistos,/los cortaron los Portugueses, entre estas diligencias se vino el día,/y encaminados los Indios en querer vengar la sangre de algunos suyos/que vieron muertos, se mantuvieron temerarios por mas de dos horas/salido el sol, expuestos á los tiros de pieza y de fusil, con espanto/y admiración de todos los Españoles, y viendo que no podían con-/seguir otra cosa, que quedar todos muertos, se retiraron con mucho/daño, pues murieron mas de 70, y salieron heridos 143 , sin/fruto alguno. En un sitio junto al foso quedaron heridos muchos,/y no podían los sanos socorrerlos, ni sacarlos sin evidente riesgo/dela vida, y para que no saliessen los Portugueses á acabarlos/de matar, se escondió en unas ruynas de casas el Sargento Mayor de/un tercio de ellos, llamado Nicolas Neengira, y se mantuvo en/dicho sitio todo el día sin comer, y con el fusil embarazó la salida á/los Portugueses, aunque disparaban dela muralla para matar á los heridos,/reconoció el Gobernador dela Colonia el daño que los suyos recibían/de dicho sitio, y echó por agua en un barquillo tres Portugueses, que/cogiéndole descubierto le tirassen á su salvo. Salió el barquillo,/y el Indio fue tan diestro y promto, que de dos tiros derribó á dos, y se volvió el barquillo sin mas fruto que llevar que/llorar, mantuvose dicho Indio hasta la noche, y con su abrigo/se retiró y retiraron á los heridos, fue maravillosa la 
constancia/del Indio Sargento Mayor, pues aguantó todo el día herido,/desde la mañana en una pierna, de una bala de Artillería,/pero quiso Dios que no peligró./

[f. 47] El día 3 de Febrero salieron los Portugueses á tratar de capitulaciones;/ y dixeron quan admirados quedaron del valor que mantuvieron los In-/dios el día 24, aunque barbaro; pues se mantuvieron tantas horas ex-/puestos á infinito fuego y que de gente, que no teme á las balas/es de quien se debe rezelar.

Concluiré las hazañas delos indios con este caso que ahora referiré,/y pudiera muchos mas, pero por no cansar los omitiré. Es de su-/poner que toda la Ciudadela se cerraba con foso y muralla, y rema-/taba esta por dos partes en el agua, la una parte fenecía acia el/sur, y la otra acia el Norte, y batía el agua, quando estaba el/mar crecido, en los baluartillos, en que remataban las dos mura-/llas, una de cada parte: para que en las bajas mareas no quedasse/passo franco á los Nuestros, pusieron los Portugueses mas adentro/muchos carros travados fuertemente unos con otros con gruesos palos,/y maromas, muy adentro del agua se aseguraban las maromas/en dos anclas, con que aunque hubiesse temporales, quedasen firmes y/no se llevasse el agua, tenían dichos carros encima muchas tablas/llenas de clavos, y [Testado: lo mismo] otras avía dentro del agua oprimiendas/de dichos carros, y con esta defensa estaban seguros los Portugue-/ses de ver por allí acometidos: daba mucha pena á nuestro Cabo/principal ver aquel embarazo, y deseando que se quitasse, propu-/solo a algunos, y luego se offreció un soldado Español de Santa Fee/á cortar los cabos nadando, y echar mar adentro los carros, pe-/ro pidió un Indio que le acompañasse: pidiéndolo dicho cabo prin-/cipal, y le offrecí quantos fuesse servido, pero como solo uno pedía,/señalé dos buenos, y ya de noche se los despaché con el Padre Joseph Texadas, que se los llevó, y esperaron que fuesse el de Santa Fee, pero hasta/la hora presente, no se sabe que se hizo de su persona, que de miedo/se escondió; pero visto que no venía, propuso el Padre Texadas á los dos Indios, que eran del Yapeyú, si se atreverían á ir, y cor-/tar los cabos, y echar al mar los carros, y dixeron que si y/lo executaron luego, y se arrojaron al agua nadando, desde/donde entraron hasta los carros más de dos quadras, (que cada una/tiene cien barras) y estuvieron nadando sin hacer pie, metidos/en ella más de media hora: cortaron los cabos y echaron al mar/los carros, y al día siguiente los llevaron con mucha fiesta á su/Real, y nos servimos de ellos por mas de dos meses para tra-/[f. 47v.]her leña y madera: assimismo trajeron algunas tablas llenas de/clavos, y algunos árboles de embarcaciones, que se servían de tener/sujetos los carros: llegaron tan cerca delos Portugueses, que los vie-/ron y oyeron, y con la noche obscura, y ruydo del agua, ni fue-/ron vistos ni sentidos de ellos, y se logró dicha hazaña sin desgracia/alguna.

Todas las cosas han de tener fin, a assi le tuvo el sitio dela/Colonia. Viniendoles á los Portugueses quatro Navíos, y en ellos/se huyeron; dejaron doce cañones, tres de bronce buenos, y nueve/de hierro, y muchissimas balas de Artillería, mucha madera,/y mas de 16 mil cueros: perdieron muchissimo, se hallaban/con mas de 800 bueyes mansos, muchissimas bacas lecheras,/mas de 600 caballos, grandiosas sementeras de todas semillas,/y todo lo perdieron: a los caballos mataron; los bueyes y las/bacas lecheras las cogieron los Nuestros y se las comieron; las/sementeras de legumbres logramos, y las de trigo, cebadas y cen/tenos, las comieron los caballos: y quando se fueron los miserables/Portugueses, ni que comer llevaban, yendo expuestos a parecer./ 
Fueronse en fin los indios a sus pueblos el día 25 de Marzo,/aviendo muerto en esta expedición mas de 100 de ellos: perdieron/muchos caballos, que se murieron en las vaquerías que hicieron,/otros en servicio del campo en las guardias, y otros murieron/por falta de pastos, y otros hurtaron los infieles, que se llegaron/al campo, [Testado: a hacer (como dixe abajo) mal], para hacernos daño: como diré después./

Desde que salieron los Indios de sus pueblos, hasta que se restitu-/yeron a ellos, se passaron ocho meses, y en el sitio quatro y me-/dio: en todo este tiempo, como ya dixe al principio, no perci-/bieron cosa alguna, ni tampoco al irse, haciendo cession grandio/samente al Rey Nuestro Señor de todos los sueldos que su Magestad les tiene/señalados en tiempo de guerra, que suman ciento y ocho mil/pesos en los ocho meses, que gastaron en este empleo. Solamente quando despues de idos los Portugueses entraron en la Colonia/llevarían como valor 500 pesos y nada mas; porque una no-/che entera antes que á ellos, los dexasse entrar el Señor Goberna-/dor, entraron quatro Compañias de Españoles, y buscaron algunos/trastos, y bien pocos y malos; y el día siguiente entraron ellos,/[f. 48] y no hallando cosa alguna, acometieron a los hierros delas , y/destrozaron tres y no mas, y dos puertas; y para que no hiciesen/en las demás otro tanto assistieron los Padres conque cerró el desorden./Los Granaderos hallaron algunos azadones y palas, y hachas y otras/cosillas de fierro, y lo tenían guardado en un rancho, no faltó delos/Indios quien lo viesse, y todos de tropel acometieron á ello, y se lo/llevaron: y esto fue únicamente lo que sacaron dela Colonia, y/los Españoles no hallaron cosa de provecho, porque en diez días que/estuvieron dados fondo los Navios Portugueses, desde que llegaron/hasta su ida, todo lo poco que tenían, lo embarcaron, y se lo lleva-/ron, y nadie ay que diga con verdad, que alguno halló alhaja, ni/buena, ni casi buena, sino únicamente lo que dixe arriba de madera, cueros, balas y artillería./

Hasta aquí lo que sucedió e hicieron los Indios en la Colonia y/su sitio; y todo lo que refiero es verdad y lo sé, como quien/se halló en dicho sitio, y como superior que era, tenia de todo/cabal noticia: y si para algun fin es necessario juramento; in-/berbo sacerdotis, lo juro puesta la mano en el pecho, etcétera./

Durante el sitio no se de quien movidos, se vinieron los Infieles/sobre nuestro campo, é hicieron mucho daño: los pocos Boanes ${ }^{24} /$ que quedaron dela guerra del mes de Febrero de 1702 se unieron/con los Guenoas ${ }^{25}$, y todos juntos se llegaron como 12 leguas de la Colonia: salían algunos Españoles e Indios á buscar carne gorda y dieron en ellos los Infieles y mataron mas de 28 Indios y/ como á seis Españoles y mulatos, y cautivaron un niño de Santa/Fee. Tenía dispuestas el Señor Gobernador varias guardias hasta Montevideo, para que le avisassen dela venida delos navios/Portugueses, que se tenían noticias, avian de venir. Sobre [testado: Ilegible] estas/Guardias dieron dichos Infieles, y mataron tres ó quatro Españoles,/tres mulatos, y tres Indios, y se llevaron muchissimos caballos de/nuestros Indios. Intentó el Señor Gobernador castigar dichos Infie-/les, y despachó para este intento dos Compañias de Españoles/con 500 Indios nuestros, y fueron mas de 1500 caballos delos/mismos indios, y por Capellan el Padre Geronimo Herran, y para/alentar y curar á los

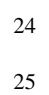

169 Martín Barrabino. Relación del jesuita José Mazo sobre la segunda toma de Colonia... 158-171. 
Indios el H. Joseph Branzaneli; pero/[f. 48v.] no pudieron dar con ellos, aunque estuvieron buscándolos mas de 24 dias y se volvieron.

Sino se huviera hecho la guerra dicha de Febrero de 1702 a los Infieles Boanes, uni/dos con los Portugueses, de ningún modo se huvieran echado los Portugueses/pues los Infieles eran Señores delas Campañas, y por consiguiente delas/bacas, único sustento del exercito en muchas occasiones,/y el delos Indios/siempre, y como ellos eran casi 800 unidos con Genoas, hubieran/destrozado nuestro exercito, dejadole sin caballos, como ellos hacen/valiéndose de su arte, y de la experiencia de aquellos sitios y pa-/rages: y créame Vuestra Reverencia que todos decimos, que fue permissiion de Dios/dicha guerra, para el feliz sucesso de esta. Ahora determi-/na el Señor Gobernador hacer la guerra á los Guenoas, y para esto con-/voca los de Santa Fee, Corrientes y de esta Ciudad 100 de cada/una, y delos Indios no se que numero pedirá que salga, y si/no se hace dicha guerra y acaban con ellos, no tendrán las Mi-/siones ni paz, ni bacas, ni comercio con esta Ciudad. Dios lo remedie todo, y guarde a Vuestra Reverencia muchos años. Buenos Ayres y Septiembre 12 de 1705.

Joseph Mazo

[Firma]

\section{Referencias Bibliográficas}

Bauzá, F. (1965). Historia de la dominación española en Uruguay. Montevideo: Biblioteca Artigas. Colección clásicos uruguayos, vol. 96, pp. 366-370.

Del Techo SJ, N. y Orosz SJ, Ladislao (1759). Decades vivorum illustrium Paraquariae Societatis Jesu Ex instrumentis literariis ejusdem Provinciae... Tyrnavia. Typis Academicis Societatis Jesu.

Ferrand de Almeida, L. (1973). A Colónia do Sacramento na época da Sucessão de Espanha. Coimbra: Facultade de Letras da Universidade de Coimbra.

Hernández SI, P. (1913). Organización social de las Doctrinas. Barcelona: Gustavo Gili ed. T. II.

Page, Carlos A. (2014). "La presencia de los jesuitas en Colonia del Sacramento". IHS. Antiguos jesuitas en Iberoamérica. Vol. 2, № 2, pp. 56-87.

Pastells, P. (1933). Historia de La Compañía de Jesús en la Provincia del Paraguay (Argentina, Paraguay, Uruguay, Perú, Bolivia, Brasil) según los documentos originales del Archivo General de Indias. Madrid: Librería General de Victorino Suárez, Tomo V.

Relación del sitio, toma, y desalojo de la colonia, nombrada el Sacramento en que se hallavan los Portugueses desde el año 1680, en el Rio de la Plata á vista de las Islas de S. Gabriel (1705). Madrid: Imprenta Real de Joseph de Contreras. 
Relación historial de los svcesos de la guerra de San Gabriel y desalojamiento de los Portugueses de la colonia del Sacramento Provincia del Rio de la Plata, desde principios de Jvlio del año 1704, hasta fines de Marzo de 1705 (1705). Lima: http://bibliotecadigitalhispanica.bne.es:80/.

Storni SJ, H. (1980). Catálogo de los jesuitas de la Provincia del Paraguay (Cuenca del Plata) 1585-1768). Roma: Institutum Historicum S.I.

Sustersic D. (2017). José Brasanelli. Pintor, escultor y arquitecto de las Misiones GuaraníJesuíticas. Asunción: Fondec.

Teschauer, C. (1922). Historia do Rio Grande do Sul, Porto Alegre, T. III.

Thun, H.; Cerno, L. y Obermayer, F. (2015). Guarinihape tecocue. Lo que pasó en la guerra (1704-1705). Memoria anónima en guaraní del segundo desalojo de la Colonia... Kiel: Westensee Verlag. 